\title{
FLUXO E INTERESSE DESENCADEADOS POR UM JOGO DIGITAL EDUCACIONAL, NO ENSINO DE MATEMÁTICA
}

Ivana Lima, PPGIE / UFGRS, ivanaufrgs@gmail.com

\author{
Gabriela Trindade Perry, PPGIE / UFGRS, gabriela.perry@ufrgs.br
}

\begin{abstract}
Resumo
Esta pesquisa teve como objetivo geral avaliar se a experiência de interesse e fluxo podem ser desencadeadas por um jogo educacional digital, comparando com uma atividade normal em sala de aula (sem computador e sem jogos). A pesquisa envolveu 89 estudantes do ensino médio noturno de uma escola pública de Porto Alegre, divididos em dois grupos: experimental - que usou o jogo "Em Busca do Santo Grau", do tipo quiz - e controle - que realizou uma atividade de pesquisa em sala de aula. Também foram realizadas entrevistas com alguns alunos. Análises quantitativas feitas por meio do teste $\mathrm{T}$ de Student indicaram diferenças significativas entre os grupos controle e experimental. As análises qualitativas também evidenciaram resultados positivos, indicando interesse situacional desencadeado pela novidade e mantido pelo envolvimento na atividade, pelos alunos que utilizaram o jogo. Constatou-se que o jogo educacional teve impacto positivo no processo educativo, de maneira tal que aqueles que jogaram interagiram durante as aulas, proporcionando maior envolvimento e colaboração com os alunos que não jogaram.
\end{abstract}

Palavras chave: jogos digitais educacionais; fluxo; ensino de matemática

\section{FLOW AND INTEREST STATE, TRIGGERED BY EDUCATIONAL DIGITAL GAME, IN MATHEMATICS EDUCATION}

\begin{abstract}
This research aimed to evaluate if the flow and interest states can be triggered by a digital educational game. The research involved 89 high school students from a public school in Porto Alegre, divided in two groups: experimental - who played the quiz-type game "Em Busca do Santo Grau" - and control - who did a research activity in classroom. This data was complemented by interviews with some students. Quantitative analyzes used Student's t-test, and indicated significant differences between groups, in favour of the experimental group. The qualitative analyzes also showed a positive result, indicating a situational interest triggered by the novelty and maintained by the involvement in the activity by the students who used the game.The educational game had a positive impact on the educational process, such that those who played interacted during the classes provided greater involvement and collaboration with students who did not play.
\end{abstract}

Keywords: educatinal digital game; flow; mathematics education 


\section{INTRODUÇÃO}

No início dos anos 80, a comunidade de pesquisa em educação animava-se com a possibilidade da inserção das tecnologias da informação em ambientes de ensino, o que se refletiu numa grande quantidade de artigos que celebravam a eficácia dessas tecnologias. Clark $(1983,1994)$ argumentava que esses estudos, na verdade, tinham erros de design, pois não faziam uma comparação justa entre situações experimentais de aprendizagem com e sem as novas tecnologias multimídia. O mesmo autor alegava que essas pesquisas não preservavam o mesmo método de instrução, de forma que não se podia ignorar a hipótese de que, na verdade, o que provocava a diferença significativa nos resultados de aprendizagem era o método, e não a mídia. Apesar de não ser frequentemente citada, a hipótese de Clark foi retomada por Joy e Garcia (2000), Lazonder e Ehrenhard (2014), Sung e Mayer (2013), Furió et al. (2015) e Perry e Eichler (2017). Sendo assim, considerou-se que não havia motivos para uma proposta de pesquisa que comparasse a eficácia, em termos de ganhos de aprendizagem, do ensino com e sem jogos digitais — pois provavelmente não haveria diferença. Contudo, há um fator que se considera ser relevante em relação a esse tipo específico de mídia: a capacidade que jogos têm de facilitar um estado de concentração intensa, de desprendimento e vontade de persistir na execução da tarefa, atingindo níveis cada vez maiores de excelência na performance.

Observa-se, também — de forma não estruturada — que os jovens dedicam muitas horas do seu dia a jogar e a descobrir novos jogos, mesmo que não sejam apenas títulos com altíssimo padrão de qualidade. Desse modo, visando articular essas intuições na forma de uma pesquisa, busca-se investigar se esse estado de engajamento intenso poderia ser despertada por um jogo educacional. De acordo com este objetivo, as seguintes hipóteses foram definidas:

H1: Há diferenças entre os grupos controle e experimental, em relação aos estados de fluxo e interesse, após as intervenções (jogo digital educacional para experimental e pesquisa sem uso de computadores para controle)?

H2: Há diferenças entre os grupos controle e experimental, em relação aos estados de fluxo e interesse, após a realização de uma atividade complementar (sem uso de computadores), que não envolve jogos digitais educacionais?

\section{TEORIAS DO FLUXO e INTERESSE}

A teoria do fluxo postula componentes que fazem parte da subjetividade, e dentre eles está o pré-requisito mais importante para o alcance dessa experiência - o equilíbrio entre desafios e habilidades (Csikszentmihalyi, 1975, 1990). Este estado foi observado em jogos, que segundo Csikszentmihalyi (1975) representam a mais típica atividade agradável e que se constitui como ato espontâneo, tendo sido descrito pelo autor da seguinte forma:

Existe um estado experiencial comum que está presente em várias formas de jogos e também sob certas condições, e que por falta de um termo melhor, vou me referir como 'fluxo'. Fluxo denota a sensação holística presente quando atuamos com envolvimento total. (Csikszentmihalyi, 1975, p.43).

Csikszentmihalyi (1975) identificou nove elementos que estavam presentes nos auto-relatos das pessoas intrinsecamente motivadas: metas claras; feedback imediato; equilíbrio entre desafios e habilidades; fusão da ação e consciência; concentração na tarefa; perda da consciência; sensação de controle; senso temporal alterado; experiência autotélica. Os três primeiros elementos são considerados condições do fluxo, enquanto 
os demais representam os estados internos e percepções de fluxo, caracterizando a experiência subjetiva de fluxo.

Estudos dos fatores motivacionais e emocionais do interesse (como as preferências pessoais e características do ambiente) conduzidos por Hidi (2006), Hidi e Renninger (2006), Renninger et al. (2014), mostraram abordagens específicas na investigação do estado do interesse na educação. Hidi (2006), por exemplo, considera o interesse como variável motivacional e afetiva que contribui para a realização das experiências, assim como um estado psicológico que ocorre durante a interação entre pessoas e seus objetos de interesse, sendo caracterizada por maior atenção, concentração e afeto. Para Hidi, o funcionamento emocional e cognitivo interage constantemente no desenvolvimento do interesse, energizando e motivando pensamentos e ações por um objeto específico. Hidi e Renninger (2006) apontaram diferenças entre o interesse e outras variáveis motivacionais: (i) inclui componentes afetivos e cognitivos; (ii) tem base biológica, no sentido de que a pessoa está envolvida física, cognitiva e simbolicamente com o objeto; (iii) resultado da interação entre uma pessoa e um conteúdo particular. Para os autores, à medida que aumenta o interesse, aumentam a atenção, objetivos e níveis de aprendizagem. Os autores propuseram um modelo sequencial de quatro fases, que representam o desenvolvimento do interesse em termos de processo afetivo e cognitivo, servindo como indicadores para mapeamento deste desenvolvimento. Cada fase do modelo varia de acordo com a quantidade de afeto, conhecimento e valor (significado pessoal) sobre o objeto.

A primeira fase refere-se ao Interesse Situacional Desencadeado, correspondendo ao estado psicológico de interesse, que tem como consequência alterações de curto prazo do processamento cognitivo e afetivo. Essa fase caracteriza-se por ser provocada pelo meio ambiente por meio de atividades instrucionais que envolvam recursos tecnológicos, informações surpreendentes ou relevância pessoal. Nessa fase o interesse é um sentimento consciente, expresso como "estar interessado", que inicia quando algo chama a atenção, e pode ser precursor da predisposição para voltar a assuntos específicos ao longo do tempo.

A segunda fase do interesse denomina-se Interesse Situacional Mantido, um estado psicológico subsequente ao estado de interesse desencadeado. Nessa fase a pessoa apresenta foco, atenção e persistência sobre um determinado objetivo. Essa fase mantém-se em função do significado atribuído à tarefa ou pelo envolvimento pessoal em atividades cooperativas ou de tutoria individual, por exemplo.

A terceira fase, intitulada de Interesse Individual Emergente refere-se a um estado psicológico de interesse em que a pessoa apresenta uma disposição duradoura para buscar reengajamento com conteúdos específicos ao longo do tempo. Nesta fase, indivíduo pode necessitar de incentivo ou apoio de outras pessoas, ou de desafios que ofereçam oportunidade para perseverar e melhorar a compreensão; também pode precisar de encorajamento quando confrontado com alguma dificuldade. O estudante com Interesse Individual Emergente pode demonstrar curiosidade sobre o conteúdo, conhecimento armazenado e valorização da retomada de tarefas relacionadas ao assunto, resultando em novos questionamentos. Assim, se for dada a escolha de fazer uma atividade, ele opta por fazê-la. 
A quarta fase, intitulada de Interesse Individual Bem Desenvolvido, refere-se ao estado psicológico de interesse com predisposição duradoura para engajar-se. São percebidos sentimentos positivos sobre o objeto, mais conhecimento armazenado e mais significado pessoal armazenado para conteúdos específicos. Há valorização de oportunidades de engajamento em tarefas de interesse individual e antecipação de etapas no processamento de conceitos. Um interesse bem desenvolvido pode fazer com que o estudante gere perguntas e respostas de curiosidade e permite que a pessoa mantenha esforços criativos de longo prazo. Há ainda o aumento da criatividade, persistência nas tarefas, perseverança em face de frustração e construção de estratégias de alto nível para a resolução das tarefas, produzindo um esforço sem esforço.

\section{FLUXO E INTERESSE: JOGOS DIGITAIS EDUCACIONAIS NO ENSINO DA MATEMÁTICA}

Buscou-se a compreensão do estado da arte do conhecimento por meio da seleção de estudos relacionados aos temas da presente tese: "fluxo", "interesse", "jogos educacionais digitais", "ensino da Matemática", e seus equivalentes em inglês. Para a inclusão no estudo, o resumo dos artigos foi lido, sendo selecionados aqueles a partir de 2015 e que contivessem todas as palavras-chave. Os bancos de dados eletrônicos pesquisados foram as bases Portal de Periódicos da Capes, Biblioteca Nacional de Teses e Dissertações, APA PsycNET, Scielo e IEEE. Os estudos selecionados são apresentados a seguir.

Hsieh et al. (2016) examinaram a relação entre as experiências de fluxo de alunos e ser desempenho na aprendizagem, assim como entre as diferenças de gênero e grau na aprendizagem com jogos. Os autores concluíram que alunos que apresentaram maior fluxo mostraram melhores resultados de aprendizagem, sendo que alunas do sexo feminino apresentaram maiores desempenhos e grandes experiências de fluxo.

Chang et al. (2017) examinaram o fluxo e as diferentes cargas cognitivas na aprendizagem, com se jogos. A amostra constituída por 103 estudantes universitários foi dividida em grupos - controle e experimental. Os resultados mostraram que a aprendizagem baseada em jogos criou mais experiências de fluxo e menos cargas cognitivas externas. $\mathrm{O}$ grupo experimental apresentou maior interesse, concentração e maior capacidade de controlar a aprendizagem.

Hamari et al. (2016) investigaram o impacto do fluxo, engajamento e imersão na aprendizagem por meio de jogos digitais. O estudo foi conduzido com 134 estudantes do Ensino Médio, ao longo de 15 semanas. Os resultados mostraram que: o envolvimento com o jogo teve efeito positivo na aprendizagem; o desafio afetou a aprendizagem; o engajamento teve forte impacto na aprendizagem percebida; imersão não teve efeito significativo na aprendizagem.

\section{MATERIAIS E MÉTODOS}

A presente pesquisa tem como objetivo geral investigar se a experiência de fluxo e interesse pode ser despertada por um jogo educacional, no contexto do ensino da Matemática no ensino médio, em uma atividade individual, por meio de uma abordagem mista, que usa métodos quantitativos (questionários) e qualitativos (entrevistas). As avaliações dos estados de fluxo foram realizadas com o EduFlow-2 de Heutte et al., (2016), e a avaliação do estado de interesse com o questionário Inventário de Motivação Intrínseca (IMI) de Ryan (1982). Ambos usam escala Likert de 7 pontos, e foram 
traduzidos pela primeira autora. O motivo da escolha destes questionários é por serem curtos e validados. As questões são mostradas no Quadro 01.

Quadro 01 - Questões do questionário aplicado aos alunos

\begin{tabular}{|c|c|}
\hline EduFlow-2 & $\begin{array}{l}\text { 1. Sinto-me capaz de lidar com as altas exigências da situação. } \\
\text { 2. Estou totalmente absorvido pelo que faço. } \\
\text { 3. Eu não estou preocupado com o que os outros pensam de mim. } \\
\text { 4. Sinto que me divirto muito. } \\
\text { 5. Sinto que controlo perfeitamente minhas ações. } \\
\text { 6. Eu não vejo o tempo passar. } \\
\text { 7. Eu não estou preocupado com o julgamento dos outros. } \\
\text { 8. Esta atividade me dá muito bem-estar. } \\
\text { 9. Em cada etapa sei o que fazer. } \\
\text { 10. Estou profundamente focado no que faço. } \\
\text { 11. Quando falo sobre essa atividade sinto uma emoção que quero } \\
\text { compartilhar }\end{array}$ \\
\hline $\begin{array}{l}\text { Inventário de } \\
\text { Motivação } \\
\text { Intrínseca }\end{array}$ & $\begin{array}{l}\text { 1. Enquanto fazia a atividade, pensava em quanto eu gosto de } \\
\text { realizá-la. } \\
\text { 2. Não me senti nada nervoso durante as atividades. } \\
\text { 3. A atividade não chamou minha atenção. } \\
\text { 4. Acho que entendi a atividade muito bem. } \\
\text { 5. Eu descreveria a atividade como muito interessante. } \\
\text { 6. Acho que entendi a atividade muito bem, comparado a outros } \\
\text { alunos } \\
\text { 7. Eu gostei muito de realizar as atividades. } \\
\text { 8. Senti-me muito tenso ao realizar as atividades. }\end{array}$ \\
\hline
\end{tabular}

Em relação à análise qualitativa, foram usadas anotações da primeira autora e entrevistas abertas com alguns estudantes de cada grupo (controle e experimental), convidados a dar seus depoimentos da experiência com/sem jogos nas aulas de Matemática. Os seguintes questionamentos foram feitos aos alunos entrevistados: "Que acharam do jogo/estudo? Tiveram dificuldade de jogar e entender o jogo/estudo? Gostaram de jogar/estudar? Jogaria em casa esse jogo/estudariam em casa? Ficaram com vontade de estudar o conteúdo do jogo em casa? Se despertou a curiosidade pelo conteúdo do jogolestudo? Você teve mais interesse em aula? Você sentiu vontade de pesquisar mais coisas em casa?".

A pesquisa foi realizada em uma escola pública de Porto Alegre (RS), que oferece à comunidade o Ensino Médio, Ensino Técnico Integrado em Administração e Ensino Técnico em Administração. Os alunos concordaram com a realização da pesquisa, que lhes foi explicada verbalmente. Além disso, todos consentiram com a participação por meio de um Termo de Consentimento Livre e Informado, que foi lido e explicado aos alunos. Aos alunos menores de idade solicitou-se a assinatura dos pais/responsáveis. A participação era voluntária e não acarretava em qualquer tipo de benefício, nem mesmo com "notas" ou "pontuações" de qualquer espécie. Os estudantes não estavam acostumados a usar jogos digitais no laboratório de informática, e tinham diferentes níveis de domínio e familiaridade com computadores e jogos digitais. 
Antes de realizar os experimentos para a coleta de dados, foram conduzidos estudos piloto, que tiveram como objetivo avaliar a sistemática experimental. $\mathrm{O}$ experimento com o uso do jogo foi realizado duas vezes, pois a quantidade de sujeitos que participou em cada turma foi pequena. Do ponto de vista do desenho experimental, não é ideal juntar os dados de duas turmas, pois os jogos, apesar de terem a mesma mecânica, tinham assuntos diferentes. Contudo, como a maioria dos alunos não completou todos os questionários, pois faltaram a uma das aulas, esta foi a alternativa para conseguir aproveitar os dados. O Quadro 2 mostra dados dos estudantes que participaram da pesquisa.

\begin{tabular}{|c|c|c|c|}
\hline \multicolumn{2}{|c|}{ Grupo experimental } & \multicolumn{2}{|c|}{ Grupo controle } \\
\hline Jogo & $\begin{array}{c}\text { Atividade } \\
\text { complementar }\end{array}$ & $\begin{array}{c}\text { Atividade } \\
\text { em sala de aula }\end{array}$ & $\begin{array}{c}\text { Atividade } \\
\text { complementar }\end{array}$ \\
\hline 48 & 9 & 10 & 22 \\
\hline
\end{tabular}

Fonte: Elaborado pelas autoras.

Os alunos de cada uma das duas turmas que participou eram sorteados para ficar em um dos dois grupos: controle ou experimental. O grupo controle permaneceu em sala de aula realizando atividades de pesquisa com auxílio de material complementar e livros, fornecidos pela professora e sem auxílio de computadores, enquanto o grupo experimental jogou o jogo "Em Busca do Santo Grau". Este é um jogo do tipo quiz, para PC, desenvolvido pela equipe Remar, no Laboratório de Objetos de Aprendizagem da UFSCar. O jogo permite que sejam customizados conteúdos de diferentes áreas do conhecimento e atividades interdisciplinares, por meio de desafios e resolução de puzzles distribuídos em fases, que podem ser acrescentadas ou retiradas, conforme o objetivo do professor. No Experimento I, o conteúdo era Matrizes, Determinantes e Sistemas Lineares, e a versão customizada encontra-se em https://tinyurl.com/y9wx75y5.No Experimento II, o conteúdo era Progressão Aritmética, e aversão customizada encontra-se em https://tinyurl.com/y5py6bqv . As atividades complementares em sala de aula tinham o mesmo tema do jogo. Ambos os grupos responderam aos questionários imediatamente após finalizarem as atividades Depois de três semanas, ao finalizar a unidade de ensino, ambos os grupos realizaram trabalho não avaliativo complementar, e ao terminarem esta atividade todos responderam os mesmos questionários pela segunda vez. Após o término desse ciclo de atividades, alguns alunos foram selecionados para relatar suas experiências de aprendizagem, por meio de entrevista individual.

Cabe ressaltar que esta pesquisa não visa comparar uma atividade com e sem uso de jogos, nem com e sem uso de computador. Sendo assim, não há como separar os efeitos da combinação "jogo + computador", não sendo possível atribuir os resultados a um ou outro. O motivo deste desenho experimental é por não se ter conseguido reproduzir a mecânica do jogo em questão em uma atividade em sala de aula, usando materiais como papel, caneta, dados, peões etc. Considera-se, contudo, que este mesmo que os efeitos de jogar e usar o computador não possam ser separados, a contribuição sobre o estado de fluxo durante atividades educacionais é potencialmente interessante. 


\section{RESULTADOS}

Iniciou-se a análise dos dados pela tabulação dos resultados do questionário de avaliação de fluxo e interesse, cujas tabelas de dados, bem como os scripts usados para análise, podem ser encontradas em https://tinyurl.com/yyl6wxpg A Tabela 1 mostra as comparações das médias dos grupos em cada uma as atividades, separadas por fluxo e interesse.

Tabela 1 - Comparação das médias das atividades (teste T)

\begin{tabular}{cccccccc}
\hline \multicolumn{4}{c}{ Interesse } & \multicolumn{3}{c}{ Fluxo } \\
\hline \multicolumn{2}{c}{ Jogo/Pesquisa } & \multicolumn{2}{c}{ Atividade em aula } & \multicolumn{2}{c}{ Jogo/Pesquisa } & \multicolumn{2}{c}{ Atividade em aula } \\
\hline Exp. & Cont. & Exp. & Cont. & Exp. & Cont. & Exp. & Cont. \\
\hline $4.91 *$ & 4.05 & $4.86 *$ & 4.19 & $5.8 *$ & 4.02 & $5.66 *$ & 4.02 \\
\hline
\end{tabular}

* Indica diferença significativa a 95\%

Os resultados são positivos em favor do grupo experimental, cujas médias foram significativamente maiores que as do grupo controle, o que indica que o jogo teria surtido efeito em fomentar o estado de fluxo.

A análise qualitativa da pesquisa reforça estas conclusões, com depoimentos largamente favoráveis à atividade com o jogo. Os relatos do grupo experimental foram positivos em relação ao uso do jogo e a resultados alcançados na aprendizagem. A transcrição da fala de alguns alunos evidenciou esse momento: "[...] foi a única matéria que consegui raciocinar"; outro aluno afirmou que "[...] só aprendo jogando" e outra aluna manifestou-se dizendo "[...] gosto de jogar e dificuldades devem ser ensinadas no jogo, como no vídeo do YouTube, ficou mais interessante a matéria”. As falas registradas dos alunos caracterizam o interesse situacional desencadeado, que, segundo Hidi e Renninger (2006), refere-se ao interesse consciente, decorrente de informações surpreendentes, novidade ou de relevância pessoal. A experiência de fluxo vivenciada no jogo pelos alunos do grupo experimental favoreceu o tempo para a aprendizagem do novo conteúdo. O relato de um aluno evidenciou essa afirmação: "o jogo ajudou muito na sala de aula, pois eu precisaria muito mais tempo de estudo para entender o conteúdo, se eu não tivesse jogado". Outra aluna afirmou que o jogo the deu mais interesse em pesquisar em casa: "o jogo me deu mais interesse de pesquisar por mim mesma, procurei na internet e ficou mais fácil de entender a matéria”. As falas registradas desses alunos apontam para o interesse situacional mantido, fase subsequente ao interesse temporário (desencadeado), que segundo Hidi e Renninger (2006) corresponde ao aumento do envolvimento de um indivíduo com um conteúdo ou objeto específico, um estado psicológico de engajamento que pressupõe atenção e tem base fisiológica (raízes biológicas). O fluxo estimulou a atenção do aluno para o avanço nas fases do jogo, conforme o relato: "a gente precisa prestar atenção no que está escrito para conseguir a resposta. Com o avanço do jogo se aprende mais e se quer avançar nas fases". Outra aluna acrescentou que o jogo agregou ao conteúdo em função do feedback imediato que proporciona: "o jogo me ajudou a observar melhor meu desempenho, porque o jogo tinha metas e fases. Na sala de aula o feedback não é tão rápido e eu não sei como eu estou".

Os relatos acima correspondem às observações de campo feitas pela primeira autora. Percebeu-se que a oportunidade que os alunos tiveram com o jogo educacional 
representou uma satisfação para todos os envolvidos e mobilizou os estudantes para a aprendizagem. Na sala de informática, os estudantes contribuíram com a pesquisa, de modo que auxiliavam uns aos outros na resolução das dificuldades apresentadas no processo, cooperavam com a professora, organizando os computadores e auxiliando colegas que não conseguiam atingir as metas ou não conseguiam compreender a mecânica do jogo. Em sala de aula, os alunos associavam os conteúdos de aula ao jogo e, durante a execução das atividades do material complementar, contribuíam verbalmente para a socialização do conhecimento. A prontidão manifesta pelos alunos, a qual contagiou a turma para a aprendizagem, pode ser explicada pelo fato de que "o interesse envolve uma relação particular entre pessoa e o meio e é sustentada através da interação" (Renninger e Hidi, 2011, p.169).

Quanto aos relatos do grupo controle, os estudantes mostraram ter tido dificuldades em interpretar os exercícios do livro e os exercícios de aula, embora tenham gostado do conteúdo desenvolvido em aula. Ao serem indagados na entrevista se o conteúdo despertou curiosidade e vontade de estudar em casa, afirmaram que o conteúdo trabalhado em sala de aula não despertou a curiosidade a ponto de se sentirem motivados para estudar por conta própria ou em suas casas. Os alunos entrevistados do grupo controle manifestaram a vontade de participar do jogo numa próxima rodada em função dos resultados alcançados por outros colegas que jogaram. A transcrição da fala de um estudante: "Senti interesse na matéria porque percebi que os outros colegas tiveram mais facilidade de aprender com o jogo, gostaria de jogar na próxima vez". $\mathrm{O}$ relato desse estudante que não jogou o jogo educacional revelou um interesse individual que surgiu a partir do relacionamento social.

Os alunos entrevistados, em ambos os grupos, manifestaram interesse de jogar o jogo educacional. Essa manifestação refere-se ao interesse situacional desencadeado, fase inicial do interesse em que algo chama atenção (novidade). Por este motivo, após a coleta de dados, foram realizadas aulas no laboratório de informática, com as turmas que participaram dos experimentos I e II. Desta forma, o compromisso ético de ofertar a todos as mesmas oportunidades foi contemplado.

\section{CONCLUSÃO}

Manipulou-se o estado de fluxo e interesse do aluno por meio do desafio do jogo "Em Busca do Santo Grau". Os testes de diferença em relação aos grupos (controle e experimental) mostraram que houve diferença nos resultados do teste de interesse e fluxo, com médias superiores para o grupo experimental. Também é importante destacar que, como foi feita a comparação entre estudantes que realizaram a mesma atividade com e sem uso de computadores, pode-se argumentar que isso pode ter contribuído para o resultado - afinal, o desenho experimental não separa a influência das variáveis "jogo digital" e "uso do computador".

Empiricamente, constatou-se que o jogo educacional teve impacto positivo no processo educativo, de maneira tal que aqueles que jogaram interagiram durante as aulas, proporcionando maior envolvimento e colaboração com os alunos que não jogaram. Os resultados mostraram que, quando jovens realizam atividades escolares com atenção sem esforço, sentem-se mais envolvidos e mais interessados. Ao passo que, quando realizam atividades que exigem concentração não-voluntária, a atenção é mantida com esforço, de forma que as experiências não se tornam particularmente gratificantes e felizes. Este efeito, conforme ressaltado anteriormente, pode também ser 
efeito da "novidade", pois estes alunos não estavam habituados a usar jogos em contextos educacionais.

Com base nessas análises, conclui-se que estímulos por meio de jogos digitais educacionais contribui para fomentar o interesse do aluno pelo conteúdo conceitual, notadamente no ensino da Matemática, visto que o aluno em fluxo concentra-se na tarefa, supera desafios e percebe seu senso de controle sobre a tarefa. As consequências dessa experiência mostraram que o aluno teve mais concentração, prontidão e vontade de repetir a tarefa.

Apontam-se as principais contribuições deste estudo, em relação ao uso de um jogo digital:

a) Contribuiu para fomentar o interesse situacional desencadeado pela novidade;

b) Contribuiu para fomentar o interesse situacional mantido pelo envolvimento do aluno na atividade;

c) Contribuiu para o aumento da prontidão, cooperação e envolvimento do aluno nas atividades de aula de Matemática;

d) Contribuiu para a compreensão de conteúdos de maneira mais rápida;

e) A interação social influenciou na ocorrência do interesse.

Com relação aos obstáculos encontrados durante o estudo, destaca-se que houve dificuldade para :

a) Mobilizar as turmas em função da infrequência dos alunos;

b) Conseguir conectividade de rede (internet);

c) Encontrar jogos educacionais digitais específicos para o ensino médio na área do ensino da Matemática;

Com relação às limitações encontradas durante o estudo, consideram-se:

a) Tamanho das amostras;

b) Intervalo de amplitude de idade da amostra.

Além disso, o uso de jogos digitais educacionais com licença aberta, passíveis de customização, como o utilizado nesta pesquisa, constitui-se como importante recurso pedagógico para docentes que não desenvolvem jogos e intencionam inseri-los em sua prática.

Sugere-se que trabalhos futuros, ao replicarem este estudo, concentrem-se no acompanhamento dos grupos ao longo de um período maior de tempo (visto que a inserção da tecnologia no presente estudo foi limitada a intervenções curta) e com estudantes de escolas diferentes.

\section{REFERÊNCIAS}

CLARK, R E. Reconsidering research on learning from media. Review of Educational Research, 53(4), 445-459, 1983.

CLARK, R. E. Media will never influence learning. Educational technology Research and Development, 42(2), 21-29, 1994.

CSIKSZENTMIHALYI, M. Play and intrinsic rewards. Journal of Humanistic Psychology, 15(3), 41-63, 1975. 
FURIÓ, D et al. Mobile learning vs. traditional classroom lessons: a comparative study. Journal of Computer Assisted Learning, 31(3), 189-201, 2015.

HAMARI, J et al. Challenging games help students learn: An empirical study on engagement, flow and immersion in game-based learning. Computers in Human Behavior, 54, 170-179, 2016.

HEUTTE, J. et al. Proposal for a conceptual evolution of the flow in education (EduFlow) model. 8th European Conference on Positive Psychology (ECPP 2016), Angers, France, 2016.

HIDI, S. (2006). Interest: A unique motivational variable. Educational research review, v. 1, n. 2 , p. 69-82.

HIDI, S.; RENNINGER, K. A. The four-phase model of interest development. Educational Psychologist, 41(2), 111-127, 2006.

HSIEH, Y; LIN, Y; HOU, H. Exploring the role of flow experience, learning performance and potential behavior clusters in elementary students' game-based learning. Interactive Learning Environments, 24(1), 178-193, 2016.

JOY, E. H.; GARCIA, F. E. Measuring learning effectiveness: A new look at nosignificant-difference findings. Journal of Asynchronous Learning Networks. 4(1), 33$39,2000$.

LAZONDER, A. W.; EHRENHARD, S. Relative effectiveness of physical and virtual manipulatives for conceptual change in science: How falling objects fall. Journal of Computer Assisted Learning, 30(2), 110-120, 2014.

PERRY, G. T.; EICHLER, M. L. Comparison of card and desktop versions of a game about periodic properties. RENOTE, 15(2), 2017.

RENNINGER, K.. Ann et al.The role of interest in learning and development. Psychology Press, 2014.

RENNINGER, K. A.; HIDI, S. Revisiting the conceptualization, measurement, and generation of interest. Educational Psychologist, 46(3), 168-184, 2011.

RYAN, R. M. Control and information in the intrapersonal sphere: An extension of cognitive evaluation theory.Journal of personality and social psychology, v. 43, n. 3, p. 450, 1982.

SUNG, E.; MAYER, R. E. Online multimedia learning with mobile devices and desktop computers: An experimental test of Clark's methods-not-media hypothesis. Computers in Human Behavior, 29(3), 639-647, 2013. 